\title{
Introduction: the aim and structure of the book
}

The fundamental importance of communication for organized action has been acknowledged since the early days of management studies. In his seminal work, Fayol (1916 [1949]) stated that well-developed organizational communication systems are essential for command and control. The foundational role of communication for modern organizations is evident in the pragmatist philosopher Dewey's assertion that communication "is a means of establishing cooperation, domination and order" (Dewey 1925 [1958], p. 202). A "linguistic turn in organizational studies" (Alvesson and Kärreman 2000), which was preceded by the seminal work conducted in the early 1970s by Silverman (1970) and Clegg (1975 [2013]), but which only became mainstream in the 1990s, claimed that discourse is substrative for organizations. According to this more radical view language is a shaping force that produces knowledge, understanding, norms and behaviour, thus making it constitutive of, rather than merely instrumental to, organization.

The central premise of contemporary organizational discourse analysis (ODA) is that language is not a neutral medium, a tool used to communicate ideas and intentions. By structuring coherent systems of meaning, coalescing in stable (but not immutable) patterns, it shapes reality and subjectivity. It becomes 'discourse'. The opportunities offered by this perspective to organizational studies are evident. It is possible to investigate the specific ways of representing and communicating information that emerge in a given organizational setting, but it is also possible to examine how ordinary ways to describe phenomena or to 'talk about things' shape knowledge and action in an organized setting. The appeal of the notion of organizational discourse rests on its promise to reveal a complex of subliminal messages and suggestions that shape the perceptions, interpretations and actions of organizational members. By uncovering the dense lattice of textual references used to describe and prescribe events and things it becomes possible to predict and explain regularities in behaviours, and even to prescribe effective ways to regulate identities (Alvesson and Willmott 2002). 
However, the linguistic substrate that produces these different meanings is also elusive. While the idea of discourse analysis seems to suggest that discourses have sufficient material consistency to be anatomized and scrutinized, their ontological status is, at best, uncertain. As a consequence, discourse risks assuming the same role in sociological theory that the Luminiferous Aether had in 19th-century physics. As Aether was the postulated medium enabling the propagation of light, so discourse becomes the made-up intermediary for justifying the existence of power/ knowledge effects. In this regard, its widespread invocation evokes the notion of culture, an analogous concept that it is considered both omnipresent and difficult to encapsulate in description.

Discourse is even more insubstantial than culture. The latter is merely hidden in the folds of social action, propagating through narratives and artefacts, and through a partial codification in explicit codes and taboos (Schein 1985 [2004]). Discourse, on the other hand, can be considered as the very fold of social action; it is what gives meaning and poignancy to stories; it is the underlying cognitive framework that gives sense to rules. Most of this constitutive role of organizational discourse is indeed invisible, because taken for granted. It appears only 'natural' that corporations are hierarchically structured, led by a professional management and devoted to maximizing efficiency and profit. Modern bureaucracies are indeed founded on the notion of instrumental rationality, whereas "expectations are used as 'conditions' or 'means' for the attainment of the actor's own rationally pursued and calculated ends" (Weber 1922 [1978], p. 24). As such they are not a neutral technology but a powerful discourse producing subjects and meanings: contemporary 'rational' organizations are predicated on a model of self-imposed discipline based on the fundamental principles of control through constant hierarchical observation and the fitting of individual diversity into normalized roles (Foucault 1979). To use a contemporary pop culture reference, discourse is like the Matrix, a world that has been weaved around us by the 'machines' created by humans (ideologies, architectures, social roles, languages, etc.) that now entrap us in an illusory but seemingly truthful reality.

A supplementary pragmatic hurdle for those who intend to employ the lens of discourse to understand organization is the impossibility of capturing the idea of discourse in a single, comprehensive, commonly accepted definition. Many different 'flavours' of discourse are in use in organizational studies such that, coming across this label, one cannot ever take for granted what concept the author has in mind. Discourse is also frequently used as a trope, to manifest allegiance to a post-structuralist paradigm. The organizational student or practitioner who tries to 
approach this fascinating perspective is faced by the daunting task of making sense of an enormous variety of different approaches to 'organizational discourse'. For any neophyte, trying to approach the debate on organizational discourse is like entering a jungle of divergent interpretations of what organizational discourse is (or is not). Points and counterpoints are intertwined like lianas and vines making the travel arduous, and finding the way is challenging because of an undergrowth of divergent definitions.

Yet the risk of objectifying discourse is intrinsically connected with any univocal statement about it. Citing the famous Foucauldian statement, according to which discourses "systematically form the object of which they speak" (Foucault 1979, p. 49) it is easy to assume that discourses are a clearly delimited subject, performing actions ('speaking'), even performing specific functions or at least having the intent of 'forming objects'. One might choose a more 'concrete' perspective, considering discourse "to cover all forms of spoken interaction, formal and informal, and written texts of all kinds" (Wetherell and Potter 1987, p. 7). Even in this case the desire to offer useful methods to analyse, measure, compare different discourses in order to understand social interactions can also lead to a reification of the concept. If discourse is reduced to some of its vehicles (the 'texts') or to its ideal content ('statements') we risk overlooking some fundamental characteristics and implications of discourse, such as the role of symbolic practices in its constitution and reproduction, its relationship with power and knowledge and its organizing function.

It is neither practical nor advisable to devise an 'ultimate definition' of what organizational discourse $i s$, and of the 'one best way' in which its analysis should be performed. It is rather more important to become acquainted with a ragged jungle of disparate interpretations, methodologies and practices. Discourse is better treated as a Kantian noumenon, a Ding an sich that can be imagined but not reduced to a set of sensible quantifications.

This book provides a succinct but wide-ranging introduction to organizational discourse. It does not attempt to offer a 'map of the jungle' since doing so would be highly impractical because organizational discourse may be thought of through the simile of a conceptual rainforest, a living organism, constantly changing and growing in unexpected directions, offering a set of ideas that can help understand the diverse but interconnected nature of this theoretical ecosystem. The book offers a phenomenology of discourse, considering the idea of discourse as an 
epistemological device to explore how symbolic practices become patterned and routinized, producing widespread ways to make sense of events and offering specific modes of organizing.

In order to compare and contrast different views on discourse and to explore the implications of applying a discursive perspective to the study of organizations and organizing I explicitly harness the power of metaphors attempting to provide a rich and - at the same time - approachable set of descriptors that can be used to study and investigate discourses. Vivid, shared images can help discussion and reflection on concepts that are too complex or vague to be contained in a univocal designation, enabling us to extend our conceptual grasp. They have an indexical value (Garfinkel 1967), in the sense that they allow us to explore and better understand certain features of an otherwise too abstract or exoteric concept by pointing us to a tangible object that is closer to our everyday reality. Metaphors can be useful heuristic tools, enabling the emergence of new meaning and new insight, thanks to the juxtaposition of ideas from different domains (Cornelissen 2005).

Each of the 'images of organizational discourse' that I propose, is used as an interpretative device to shed light on different attributes of discourse and to connect several research perspectives that share discursive roots (e.g. organizational culture, organizational identity, organizational fashions, organizational rhetoric, etc.).

I commence the book positioning discourse analysis in the broader paradigm of studies that examine the linguistic and cultural aspects of organizing (Chapter 1); then I review alternative attempts to provide taxonomies of varieties of ODA and discuss some of the ontological and epistemological challenges encountered by discourse analysts (Chapter 2). I subsequently describe how the use of metaphors can be useful to reflect on the issues surrounding discourse analysis (Chapter 3). Three different metaphors are employed to connect several approaches to organizational studies that have their conceptual roots in discourse, with the purpose of extending the readers' awareness of the various implications of ODA: discourse as a map, discourse as an organizing device, and discourse as a mask (Chapters 4-6). In lieu of a conclusion, Chapter 7 provides a concrete exemplification of the application of ODA, in which the heuristic potential of the approach is employed to critically describe a complex interorganizational field of practices that underlies the global institution of business education. Applying a discursive lens to this specific object is of particular interest and not just because of the dimension and complexity of the phenomenon, or thanks to the richness of the empirical textual material, constituted by a large corpus of literature presenting the history of business education and discussing 
avenues for its future reform. The relevance of this discussion resides in the mutually constitutive relationship that business education, seen as a global, paradigmatic discourse, has with all possible local forms and manifestations of organizational discourses. Despite their attempts to project an image of themselves as neutral, scientifically-driven knowledge brokers, business schools' discursive practices are neither value free nor immune from the rhetorical and ideological undercurrents that affect their objects of study. Moreover, education is obviously a discursive practice, based on symbolic performances and aimed at disciplining learners (Foucault 1979), and by training generations of aspirant and practising managers and entrepreneurs business schools have a remarkable influence on the (re)production of organizational discourses. This exemplification highlights the interpolation of the symbolic and pragmatic side of social life, bringing to life the issue of power and its constitutive effects, and thus showing the potential for a productive (of ethical awareness, positive innovation and managerial reform), rather than merely descriptive, use of ODA.

\section{REFERENCES}

Alvesson, M. and Kärreman, D. 2000, 'Taking the Linguistic Turn in Organizational Research: Challenges, Responses, Consequences', The Journal of Applied Behavioral Science, vol. 36, pp. 136-58.

Alvesson, M. and Willmott, H. 2002, 'Identity Regulation as Organizational Control: Producing the Appropriate Individual', Journal of Management Studies, vol. 39, pp. 619-44.

Clegg, S.R. 1975 [2013], Power, Rule and Domination, Routledge, Oxon.

Cornelissen, J.P. 2005, 'Beyond Compare: Metaphor in Organization Theory', The Academy of Management Review, vol. 30, pp. 751-64.

Dewey, J. 1925 [1958], Experience and Nature, vol. 1, Dover Publications, New York.

Fayol, H. 1916 [1949], General and Industrial Management, Pitman, London.

Foucault, M. 1979, Discipline and Punish: The Birth of the Prison, Vintage Books, New York.

Garfinkel, H. 1967, Studies in Ethnomethodology, Prentice Hall, Englewood Cliffs, NJ.

Schein, E.H. 1985 [2004], Organizational Culture and Leadership, 3rd edn, Jossey-Bass Publishers, San Francisco, CA.

Silverman, D. 1970, The Theory of Organisations: A Sociological Framework, Heinemann Educational, London.

Weber, M. 1922 [1978], Economy and Society: An Outline of Interpretive Sociology, University of California Press, Berkeley, CA.

Wetherell, M. and Potter, J. 1987, Discourse and Social Psychology: Beyond Attitudes and Behaviour, SAGE Publications, Newbury Park, CA. 
Marco Berti - 9781784717056

Downloaded from PubFactory at 04/26/2023 05:55:38AM via free access 